\title{
The Concern With Truth, Sense, et al: Androcentric or Anthropocentric?
}

\author{
A. W. Moore
}

\begin{abstract}
$\underline{\text { Abstract }}$
In her book Re-visioning Gender in Philosophy of Religion, Pamela Sue Anderson generously discusses some of my ideas. In particular, she considers my views about a certain kind of philosophical nonsense. She argues that I am not interested in engaging seriously with such nonsense; and that my not being interested in engaging seriously with it betrays my gender. This essay is a response to Anderson's discussion. I argue that she is guilty of certain errors, both exegetical and philosophical. In the course of doing so, I raise some issues about what we can aspire to as philosophers. These issues in turn bear on the relation between philosophy and the feminine, between philosophy and the masculine, and between philosophy and the human. Towards the end of my essay I urge that the third of these relations-the relation between philosophy and the human-is of far greater significance than either of the other two.
\end{abstract}

It is a great honour to contribute to this collection of essays in memory of my friend Pamela Sue Anderson. Of course the circumstances mean that the pleasure of doing so is mixed with sadness. Anderson and I spent many happy hours discussing philosophy together. It is impossible for me to convey how much I miss our discussions.

In her written work Anderson generously paid a good deal of critical attention to my own. This is especially true of her last book Re-visioning 
Gender in Philosophy of Religion. ${ }^{1}$ I hope it will not appear too self-indulgent if I use this occasion to respond to some of what she said. I believe that she was guilty of certain errors, both exegetical and philosophical. But only someone who was a stranger to philosophy, and indeed to Anderson herself, could think it the least paradoxical that I choose, as my tribute to her in this context, to dwell on what I take to be such errors. The discussion will eventually turn into a more general reflection on the nature of philosophy. What I have to say at that point will be more speculative. It will concern issues about which I am altogether less confident what the implications of Anderson's views are and how, if at all, I would oppose them-though it speaks volumes about the richness and interest of Anderson's work that it so much as leads us in that direction.

Much of my own work has revolved around a number of dualities. In particular, much of it has revolved around the following five dualities:

(1) true/false

(2) absolute/perspectival

(3) effable/ineffable

(4) sense-possessing/sense-lacking

(5) finite/infinite.

Before I go any further, I want to make brief comments about the fourth and fifth of these. I begin with a comment about the fourth. This comment is largely terminological. I would like to have characterized this fourth duality by simply writing “sensical/nonsensical." But standard English, notoriously and maddeningly, does not give us "sensical." (Or at any rate, it does not yet give us "sensical." I suppose it is just a question of time. People are increasingly availing themselves of it.) Would "meaningful/meaningless" have suited my purposes here-or, for that matter, "meaningful/nonsensical"? No. This is because I like to distinguish between that which has sense and that which has meaning: the latter, for me, is a broader notion. For reasons that I am about to sketch, I believe that there are ways of putting language to use

\footnotetext{
${ }^{1}$ (Farnham: Ashgate, 2012). All unaccompanied references will be to this book.
} 
which, on the one hand, exploit the meanings of the words involved but which also, on the other hand, result in something that is strictly speaking nonsensical. And when language is put to such use, I see some rationale for classifying what results as having meaning but lacking sense. "Meaningful nonsense" is therefore not, on my lips, oxymoronic.

Concerning the fifth duality, I have a comment about the order of the two terms. Looking at how I have couched the other four dualities, you may suspect that $I$ intend an alignment of sorts. In particular, you may suspect that I see some sort of priority of the first term over the second in each case, or some sort of superiority of the first term to the second. And you might then be surprised that I have not written "infinite/finite" in the fifth case. This would be quite wrong. For one thing, I intend no such alignment in the first four dualities. Secondly, even if I did, it would be entirely unstraightforward how the finite and the infinite related to it. I shall come back to both of these points.

Now Anderson discusses all five of these dualities, largely in the context of two others about which I say very little:

(6) male/female

and, perhaps differently,

(7) masculine/feminine.

Why perhaps differently? Well, here I must tread with caution. There are three reasons for this. First, and most basically, I have no expertise in this area. In particular, I have no expertise in feminism, where any distinction between the sixth duality and the seventh is liable to be especially significant. Secondly, and disconcertingly, I am nevertheless aware that practically nothing in this area is uncontroversial. Moreover, much of the controversy is not between feminists and those whose ideas they are critiquing, but among feminists. Thus it is controversial to what extent there really is any serviceable, robust, and objective distinction between the male and the female; to what extent there is any such distinction between the masculine and the 
feminine; and to what extent there is any such distinction between these two dualities themselves, or, more broadly, between sex and gender, of which this is supposed to be an instance. ${ }^{2}$ Thirdly, I find it hard to know where exactly Anderson situates herself with respect to these controversies or how this relates to her discussion of my own work.

But I do know that, underlying Anderson's discussion of my work, is a constant concern with how evaluation infects our philosophical discourse, and in particular with how it does so through the use of what Bernard Williams calls "thick" concepts, that is to say concepts that have both an evaluative aspect and a descriptive aspect. (A standard example of a thick concept is the concept of infidelity. This has an evaluative aspect inasmuch as, in calling someone unfaithful, you censure that person. But it also has a descriptive aspect inasmuch as you are not entitled to call someone unfaithful unless that person has gone back on some relevant agreement.) ${ }^{3}$ The question arises-for anyone, but particularly for anyone with Anderson's interests-what sort of thickness, if any, there is in any of the concepts involved in these seven dualities. And this in turn obviously relates back to the issue of what sort of alignment there is among them. As I have already indicated, I assume no privileging of the first term in each duality over the second, not even when attention is confined to the first four dualities. In fact I assume no interesting alignment at all. This is not to deny that the concepts involved are thick. But, if they are, the thickness is in each case far from straightforward; and the relation between the thickness of each to the thickness of all the others is further still from straightforward.

\footnotetext{
${ }^{2}$ See e.g. Anne Fausto-Sterling, Sexing the Body: Gender, Politics and the Construction of Sexuality (New York: Basic Books, 2000); Elizabeth V. Spelman, Inessential Woman: Problems of Exclusion in Feminist Thought (Boston: Beacon Press, 1988); Judith Butler, Gender Trouble, $2^{\text {nd }}$ edn (London: Routledge, 1999); and Mari Mikkola, "Feminist Perspectives on Sex and Gender", in The Stanford Encyclopedia of Philosophy, ed. Edward N. Zalta, https://plato.stanford.edu/archives/win2017/entries/feminism-gender/.

${ }^{3}$ See e.g. Bernard Williams, Ethics and the Limits of Philosophy (London: Routledge, 2006), 129-130 and 140-141. This idea of a thick concept structures much of Ch. 6 of Anderson's book: see e.g. 113 .
} 
I hope I will be forgiven if, as a prelude to amplifying on these remarks, I give a lightning sketch of some of my central views about the first five dualities. ${ }^{4}$

Directly relevant to all but the fifth is what I call a representation. By a representation I mean anything which has content and which, because of its content, is either true or false. (Representations thus include assertions, thoughts, judgments, theories, and the like.) Here already the true/false duality is in play. But only the most extreme of philosophical sceptics would deny that it has any right to be, or that it has any significant claim on our attention. Anderson would certainly not deny either of these things.

Among representations - and this is where I invoke the second dualityI distinguish between those that are absolute and those that are perspectival. Absolute representations are not coloured by the feelings, concerns, or values of those who produce them. Nor does their content depend on their location, in any literal or metaphorical sense (in the way, for example, in which the content of a tensed representation depends on the time at which it is produced). In other words, absolute representations are not from any point of view. Perspectival representations are. Representations of both kinds, I argue, are possible. I also argue that it is representations of the former kind that scientists, and more specifically physicists, aspire to produce; and that, if ever anybody does produce such a thing, then it will have to be couched in scientific, and more specifically physical, terms. If ever anybody produces such a thing... I am not committed to the view that anybody ever actually has done so or will do so.

The first two dualities cut right across each other. Absolute representations can be true or false. Perspectival representations can be true or false. Whatever privileging there may be of the true over the false, it does nothing to encourage a privileging of the absolute over the perspectival. Nor, in my view, does anything else. The aspiration to produce absolute representations has its rationale in a certain scientific context. Outside that context it has no rationale whatsoever. In particular-this is important for

\footnotetext{
${ }^{4}$ What follows draws principally on my Points of View (Oxford: Oxford University Press, 1997).
} 
what will come later-it has no rationale in philosophy. Nor is the scientific context itself in any relevant sense privileged.

The third duality is between the effable and the ineffable: this applies within states of knowledge. A state of knowledge is effable if and only if it is a representation, in other words if and only if it has content which makes it true or false-in fact true, given that it is a state of knowledge. But there are, I believe, states of knowledge, indeed important and familiar states of knowledge, that are not of this kind, states of knowledge that lack content and are therefore ineffable. Someone who has ineffable knowledge thereby knows how to do certain things, or knows what it is for certain things to be the way they are, or something of that sort; but he or she does not thereby know that anything is the case. ${ }^{5}$

If anyone were to attempt to put such ineffable knowledge into words, then the attempt would be a failure. But the result might be of interest for all that. And indeed I believe that, if the attempt were suitably executed-which admittedly raises some large questions about what would count as a suitable execution, though I shall not dwell on these questions now-then the result would serve to individuate the knowledge, and might even serve to convey it. Even so, the result would strictly speaking be a piece of nonsense: this is where the fourth duality is pertinent. (It is also what I had in mind when I spoke earlier of meaningful nonsense.) What would be an example? One example, I argue, would be the sentence: "Absolute representations are not possible." But why do I say that this would be a piece of nonsense, rather than simply false? Because, granted the soundness of my argument that absolute representations are possible, or in other words that it is false that they are not, this sentence could not serve its function without being hedged with qualifications that prevented it from being interpreted as that falsehood; and indeed, crucially, that prevented it from being interpreted at all.

Another example would be the sentence: "The infinite exists." 6 Why would this be nonsensical? Because our very notion of the infinite precludes

\footnotetext{
5 A possible exception is someone who has knowledge of a necessary truth: see my "Ineffability and Nonsense," in Proceedings of the Aristotelian Society, Supp. Vol. 77 (2003): 169-193, n. 16. I shall ignore that complication in what follows.

6 This is what Anderson is alluding to at 70, where she writes, "According to Moore, ineffability is 'shown' in 'images of infinitude'," though I would not express it like that.
} 
its existing. It is as if the infinite is too great for that. ${ }^{7}$ Or, in Wittgensteinian terms more conducive to the current point, it is as if the very "grammar" of the word "infinite" prevents it from directly characterizing anything in reality. ${ }^{8}$

Am I myself producing nonsense in peddling these ideas, and (in particular) in specifying the sort of nonsense that accrues from attempting to express the inexpressible? I do not think so. I think I can avail myself of the distinction between discussing nonsensical uses of words and indulging in such uses. It is not necessary to talk nonsense in order to talk about nonsense: one can say, quite truly, “Brillig' has two syllables." I aspire, in my discussion of these issues, to produce nothing but sense, and indeed to produce nothing but the truth.

In a conference on the work of Derrida in which I participated and which is the focus of much of Anderson's own discussion (see Ch. 4), I gave this some context by saying that the kind of philosophy that I practise, which I called "conceptual philosophy," "has a commitment to the truth."9 But it is a commitment of a distinctive sort. Derrida, in his reply, pointed out that there are other, quite distinct sorts of commitment to the truth, including a sort that he saw as part of the kind of philosophy that he practised. One can be committed to the truth by questioning it, indeed by questioning its very possibility, and by taking nothing for granted about how it relates to language or to sense. ${ }^{10}$ So be it. The key point, to repeat, is that I aspire, in my discussion of these issues, to produce nothing but the truth.

Now I briefly relate all of this to the sixth and seventh dualities in my book Points of View. ${ }^{11}$ I admit there that current scientific theories may, in Sandra Harding's phrase, "bear the mark of their collective and individual creators," and that the creators in turn may "have been distinctively marked as

For clarification of my use of the terminology of "showing," see Points of View, Ch. 7, esp. $\S 3$.

${ }^{7}$ Cf. Iris Murdoch, Metaphysics as a Guide to Morals (Harmondsworth: Penguin, 1993), 508 .

${ }^{8}$ Cf. Ludwig Wittgenstein, Philosophical Remarks, ed. Rush Rhees and trans. Raymond Hargreaves and Roger White (Oxford: Blackwell, 1975), §XII.

9 "Arguing With Derrida," in Arguing With Derrida, ed. Simon Glendinning (Oxford: Blackwell, 2001), 59.

${ }^{10}$ Jacques Derrida, "Response to Moore," in Arguing With Derrida, ed. Simon Glendinning (Oxford: Blackwell, 2001), 84.

${ }^{11}$ See Points of View, 101-102 and 108-109. 
to gender, class, race, and culture."12 This does not trouble me. As I have already made clear, my argument is an argument for the possibility of absolute representations, not for their actuality. I also admit that some of the crucial concepts that I myself use to frame this discussion, including some of the concepts that appear in the first five dualities, contain an element of perspective. ${ }^{13}$ This is because they cannot be exercised except from some interpretative point of view. I would be happy to go further and admit that some of them contain an element of thickness, and that they cannot be exercised except from some evaluative point of view. But, if that is so, it has no implications for how I view either the sixth or the seventh duality. There is, as I have been at pains to insist, no presumed alignment in the first five dualities. A fortiori there is no presumed alignment that extends from them to the other two; or to the duality between what is to be valued and what is to be disvalued; or, heaven forefend, to all three. For, as I emphasize in my book, although there undeniably has been an ideological alignment of the true and the absolute and the scientific with what is to be valued and with what is either male or masculine (a kind of veneration of scientific practice as a detached, authoritative, rational domination of mother nature), I want no part of it. And I see no reason why the dualities themselves should not survive any such (false) ideology.

But Anderson recoils. She attends to each of the first five dualities and suggests that there is, in my work, an implicit privileging in each of them of the first term over the second; and that this privileging, in fact my very concern with each of these dualities, betrays my gender, precisely what I am keen to deny.

Before I go any further, I want to note straight away that Anderson's discussion becomes somewhat muddied in the case of the fifth duality. This is not a criticism. It relates back to peculiarities of the infinite: the subject matter itself condemns whoever engages with it, at least in this sort of context, to a kind of unclarity. In fact I applaud what Anderson says in this connection. In a section of her book entitled "The infinite and gender: an ancient question"

\footnotetext{
${ }^{12}$ See Sandra Harding, The Science Question in Feminism (Milton Keynes: Open University Press, 1986), 15.

${ }^{13}$ See Points of View, $98-99$.
} 
(75-79), she discusses Grace Jantzen's interesting classification of the urge for infinitude as "a masculine or male obsession," and then notes that, at the beginning of Western philosophy, most notably among the Pythagoreans, it was the urge for finitude, or the privileging of finitude, that had the (far) better claim to that title. Indeed Anderson makes significant capital out of such ambivalence, capital that directly subserves her project. For, as she further says, "considering why the infinite is given this or that gender will give us new understandings for the re-visioning of gender" (79). This all strikes me as fundamentally correct-though I also think that the muddying of this part of Anderson's discussion, despite how much of it depends on peculiarities of the infinite, should make us wary of expecting any engagement with the first four dualities to escape the same fate.

Still, let us return to what Anderson says about the first four dualities and to my discomfort with it. Adverting to the conference on the work of Derrida that I have already mentioned, she comments on the all-male list of speakers and remarks that "the philosophical assumption seemed to be one of arguing from a gender-neutral perspective, yet the maleness was conspicuous from another perspective" (67). Later there is a characteristically teasing passage where she suggests that, in my own talk of ineffability-of that which cannot be put into words-I may in fact mean no more than that which cannot "be put into the words of a particular (privileged) perspective within the dominant conceptual scheme" (72). And later still we find discussion of the fact that I, in contrast to Derrida, want to eschew nonsense in favour of what not only has a sense but is true:

[Moore]... distinguishes himself from Derrida in insisting that the affirmation of truth is an ultimate concern... Moore is only willing to play with nonsense [i.e. Moore is only willing to engage in playful talk about nonsense-he is not willing to produce it himself], while Derrida ironically seems far more serious about nonsense!... Moore does not aim to produce nonsense, or to engage seriously with it. (73-75, emphasis added)

She expands on this in relation to the early Wittgenstein: 
Wittgenstein's relation to... nonsense... as set out in his Tractatus ${ }^{14}$ begins to seem closer to Derrida's relation to nonsense (since he takes it very seriously) than Moore's detached play with nonsense. (81)

Much of Chapter 6 of her book develops this idea, dealing as it does with the privileging of truth over falsehood and nonsense.

But I demur. To anyone who knows how great my admiration for Wittgenstein is, this reference to his Tractatus should already give pause. As Anderson herself correctly insists later, "it could be that the negative connotations of "nonsense' should be ignored" (84). Indeed they should. There is an irony here. The passage in which Anderson says this involves a rather spectacular failure of proofreading: it is presented as though it were a quotation from me, whereas it is Anderson's own text, written in propria persona and supposedly contra me. The irony is that what she says here is something which in fact, as I have just indicated, I would be only too happy to endorse. ${ }^{15}$ I shall come back to this.

But there is more. It is not just that Anderson represents me as denigrating nonsense. She also thereby, however implicitly, represents me as denigrating the female and/or the feminine. For the whole thrust of the chapter from which I have been quoting is that the ineffable, and likewise the nonsensical that attends it, are to be thought of in female or feminine terms. Anderson talks about female mystics, and about the nonsense that they produce. She distances me from them. She writes:

Moore does not intend to produce nonsense. Instead, he aspires to produce truth. Yet... doesn't Moore belie his own gender

\footnotetext{
14 Ludwig Wittgenstein, Tractatus Logico-Philosophicus, trans. D.F. Pears and B.F. McGuiness (London: Routledge, 1961).

${ }^{15}$ I have another, entirely unrelated and frivolous reason for noting this error in Anderson's text. It reminds me of a bizarre mistake of predictive texting in a message that Anderson once sent me, which resulted in much mutual hilarity. In response to my question whether she was able to accompany me to some event at short notice, instead of replying that she could not because she had a graduate student round helping her to proofread, she replied that she could not because she had a graduate student round helping her to procreate.
} 
bias, opting for the sense of effable knowledge, when the female mystic's know-how and the wise woman's tales fail to produce sense-and so truth[?] (84-85)

She goes on to cite how Irigaray makes nonsensical play with images of infinitude; and how Jantzen recognizes the importance of stretching language to represent the "inexhaustible fecundity" of the divine (85). Finally, at the very end of the chapter, she says that we must move beyond "traditional answers to the philosophical question of ineffable knowledge," which are "inadequate insofar as they have failed to acknowledge a necessary tension in our gendered relations to the finite and the infinite, as both corrupting and enabling”(87). She continues:

Philosophy of religion as practised by both those who aspire to produce truth and those who engage seriously with nonsense... can acknowledge this tension as the first step towards new ethical and epistemological relations between women themselves, men themselves, and women and men, of different material and social perspectives. (87)

All of this, I confess, leaves me bemused.

There is, in my discussion of these issues, no privileging of sense over nonsense. True, I aspire, in any such discussion, to produce only the former, as I have already said. In fact I aspire, whenever I write philosophy, to produce only the former. But this is not because I disparage the production of the latter, or at any rate not all of it. Some of it I disparage. Indeed most of it I disparage. So would Anderson. The production of nonsense that is effectively nothing but a botched attempt to produce sense is certainly to be disparaged. But that is not what Anderson is concerned with here. She is concerned with something of the sort that I described earlier: the creative production of nonsense in a suitably executed attempt to put into words knowledge that cannot be put into words, the sort of thing that may even serve to communicate the knowledge, the sort of thing that I have indicated I am prepared to count, despite its nonsensicality, as meaningful. I do not go in for that practice myself: I confine 
my engagement with such nonsense to quotations either of other people's work or of certain very elementary examples. But this is not because I disparage the practice. It is because I take myself to be not very good at it. Other philosophers are very good indeed at it. Thus I believe that Wittgenstein's Tractatus consists largely in the production of such nonsense; also that it is one of the great philosophical texts; and indeed, if you were to press me, that it is one of the great works of art. The reason why I aim in my own philosophical practice to produce nothing but sense, and more specifically nothing but the truth, is simply that such is the style of philosophy that I take to be my own métier. I do not deny that other styles are possible. And I do not say that other styles are inferior.

It seems to me, then, that Anderson is imposing an unhelpful grid here. In particular, I find her use of the categories of male and female unhelpful. In fact I think there is a real issue, ironically, about what, if anything, prevents us from classifying it as sexist. The thought that it is sexist connects, I believe, with the controversies to which I adverted earlier concerning the sixth and the seventh dualities. There is a threat of self-stultification hereabouts: the threat of meeting an unacceptable stereotyping in regard to such categories with more of the same. Evading this threat, for anyone who seeks to champion the cause of women, means striking a delicate balance. For one staple of championing the cause of women is, precisely, fighting an unacceptable stereotyping of women; but fighting it too hard, in particular fighting it hard enough to undermine any sort of essentialism concerning the category of women, may mean that there is nothing left to champion. To quote Mari Mikkola:

If feminist critiques of the category women are successful, then what (if anything) binds women together, what is it to be a woman, and what kinds of demands can feminists make on behalf of women? ${ }^{16}$

\footnotetext{
${ }^{16} \mathrm{Op}$. cit. in n. 2. For discussion of some of the issues that arise here see: Natalie Stoljar, "Essence, Identity and the Concept of Woman," in Philosophical Topics 23 (1995): 261293; and Linda Martín Alcoff, Visible Identities: Race, Gender, and the Self (Studies in Feminist Philosophy) (Oxford: Oxford University Press, 2006).
} 
There are, to be sure, various tactics that suggest themselves for confronting this dilemma, including deliberately embracing a kind of sexism in a spirit of deconstruction. I certainly do not mean to suggest that I have found some insuperable objection to what Anderson is doing with the categories of the male and the female in this chapter of her book. I simply say that I do not find it helpful.

Now there is, of course-and this is something that I concede in Points of View ${ }^{17}$ - a very obvious, very basic, and potentially very damning objection to these attempts of mine to deflect Anderson's critique, and it would be crass for me not to acknowledge it. I mean the objection that I am simply betraying my own male point of view once again. Anderson herself makes some telling points that pertain to this objection in a later chapter where she contrasts ways in which male thinkers manage to make themselves heard with ways in which female thinkers struggle to do so, implying that a certain lack of selfconsciousness is integral to the former (see e.g. $126 \mathrm{ff}$.). Later she refers to "a keen sense of injustice which is often not noticed by a privileged thinker who seems to be reasoning about abstract matters" (137). Obviously it would be unacceptable for me simply to dismiss such thoughts. I would face my own threat of self-stultification if I did.

Nor do I. Such thoughts constitute a crucial caveat to all that I have been saying. If I have been saying it from a male point of view, and if I have been doing so in such a way that I count as benighted, and if the situation is remediable, then I am, I hope, receptive to whatever remedy is available. If the situation is not remediable, and if this is not due simply to some limitation of mine, then that is itself of real philosophical significance. Either way, more needs to be said, even if it cannot be said by me.

At any rate I not think of myself as saying what I have been saying from a male point of view. Nor do I think that the kind of philosophy that I practise can be practised only from a male point of view. If I could be persuaded that this were the case, then it would force me to rethink my whole conception of the discipline.

${ }^{17}$ See 109. 
I want to close by saying a little more about that conception. ${ }^{18}$ As I remarked much earlier, I deny that it is the business of philosophers to produce absolute representations. Philosophers have to pursue their discipline from some point of view. And I can see the appeal of the idea that they would do well to pursue it from a female point of view, at least to a greater extent than they currently do. Such an idea might even appear to sit well with my denial that the kind of philosophy that I myself practise can be practised only from a male of point. For this denial does not have to be understood as a claim to neutrality. It can be understood as the claim that the kind of philosophy that I practise can be practised just as effectively from a female point of view as it can from a male point of view, a claim that encourages practice of it from both. To repeat: I can see the appeal of such an idea. I think it contains an important insight: the insight, to put it in a way that I hope does not sound too flippant, that philosophy needs to be more in touch with its feminine side. Nevertheless, I do not believe that this insight is well expressed in terms of a female point of view. Talk of a female point of view, at least in this connection, still seems to me too close for comfort to what I find unhelpful in the grid that Anderson imposes.

Admittedly, in trying to find a better way to express the insight, I am, in effect, confronting the very dilemma that I said Anderson confronts: that of finding a way to proclaim the feminine in philosophy without being sexist. I cannot, here and now, offer a satisfactory response to this dilemma. But let me sketch what I think such a response would look like. I think it would begin with the thought that what is really important here is not the relation between philosophy and the feminine, or between philosophy and the masculine, or between philosophy and either the male or the female, but rather the relation between philosophy and the human. I follow Bernard Williams in conceiving of philosophy as a humanistic discipline. ${ }^{19}$ What this means is that philosophy

\footnotetext{
${ }^{18}$ One of Anderson's own concerns is with the nature of philosophy. Her specific focus is the philosophy of religion; but it can scarcely be denied that this has, and is intended to have, repercussions for the discipline as a whole: $c f$. 47-48.

19 See Bernard Williams, "Philosophy as a Humanistic Discipline," reprinted in his Philosophy as a Humanistic Discipline, ed. A.W. Moore (Princeton: Princeton University Press, 2006). I try to defend the view in "Sense-Making From a Human Point of View," in The Cambridge Companion to Philosophical Methodology, eds Giuseppina D’Oro and Søren Overgaard (Cambridge: Cambridge University Press, 2017).
} 
is in an important sense anthropocentric. It is an attempt, by human beings, from their unique position in the world, to make sense both of themselves and of that position. This is to be distinguished from the claim that philosophy is a branch of anthropology. Philosophy is not the scientific study of human beings; nor of any of the peculiarities that mark the way of life of any human beings. For it is not the scientific study of anything. It does nevertheless have a fundamental concern with human beings and with what it takes to be one. And it is properly pursued, at the most fundamental level, from a human point of view. In so far as this has purchase specifically on women, it is because the best philosophy reflects the varieties of human experience, both male and female. But the way in which it does this is by making truths about the varieties of human experience available to everyone.

As far as the differences between the male and the female are concerned-or the differences between the masculine and the feminine, if these are different differences-that these are important, and in particular that they are important to philosophy, I do not dispute. Nor do I dispute that they are profound. But their importance and their profundity, within the ambit of the human, seem to me as nothing compared with the importance and the profundity of what unites the human, or with the importance and the profundity of the differences between the human and the non-human. In Spinozist terms, and hence in terms that I know would have been congenial to Anderson herself, the common notion "human" seems to me incomparably more significant, to each and every one of us, than the common notion "male" or the common notion "female." 20 I take that to be a quite general truth. But I also take it to be a truth with a very particular and very significant application to philosophy, for the reasons sketched above.

None of this, I barely need to say in conclusion, constitutes a decisive objection to anything that Anderson was doing in her work, still less to the general tenor of that work. I have rather expressed a certain dissatisfaction with what she was doing, and gestured at some of what I would do instead.

${ }^{20}$ See Benedictus de Spinoza, Ethics, in Spinoza: Complete Works, ed. Michael L. Morgan and trans. Samuel Shirley (Indianapolis, Ind.: Hackett Publishing, 2002), Pt II, Prop. 37 and Prop. 40, Scholium 2. See also ibid., Pt IV, Props 35-37 (couched admittedly in what would now be classified as sexist terminology). 
Does this betoken a kind of vulnerability? It leaves me feeling vulnerable, in particular by challenging my self-image as a philosopher. Anderson would certainly have been sensitive to this and would have wanted to accommodate it in our ongoing conversation about these issues. I only wish that she were here now to continue that conversation.

Prof. A. W. Moore

St Hugh's College

St Margaret's Rd

Oxford

OX2 6LE

Email: adrian.moore@st-hughs.ox.ac.uk 